\title{
Report on Death of Dwarf Sperm Whale, Kogia sima (Order: Cetacea: Family: Kogiidae) in Vedalai Shore of Mandapam, Gulf of Mannar
}

\author{
Koushik Sadhukhan $^{a^{*}}$, C. H. Ramesh ${ }^{\text {a }}$, T. Shanmugaraj ${ }^{a}$, \\ M. V. Ramana Murthy ${ }^{b}$ and S. Satish ${ }^{c}$ \\ ${ }^{a}$ National Centre for Coastal Research (NCCR), Ministry of Earth Sciences (MoES), NCCR Field \\ Research Centre, Mandapam Camp, Tamil Nadu-623519, India. \\ ${ }^{b}$ National Centre for Coastal Research (NCCR), Ministry of Earth Sciences (MoES), Pallikaranai, \\ Chennai-600 100, Tamil Nadu, India. \\ ${ }^{c}$ Gulf of Mannar Marine National Park Authority, Kadampa Nagar, Ramnathapuram, \\ Tamil Nadu-623503, India.
}

Authors' contributions

This work was carried out in collaboration among all authors. Authors KS and SS have done the field survey and data collection. Authors KS, CHR, TS writes and edits the manuscript. Author MVR coordinate the whole study. All authors read and approved the final manuscript.

Article Information

DOI: 10.9734/ARRB/2022/v37i130475

Open Peer Review History: This journal follows the Advanced Open Peer Review policy. Identity of the Reviewers, Editor(s) and additional Reviewers, peer review comments, different versions of the manuscript, comments of the editors, etc are available here: https://www.sdiarticle5.com/review-history/78257

Short Communication

Received 05 December 2021

Accepted 09 January 2022

Published 10 January 2022

\section{ABSTRACT}

Aims: Present study aims to highlight an accidental death of a male Dwarf Sperm Whale scientifically known as Kogia sima which found to be as Least Concern (LC) as per IUCN Red List data. Kogia sima represents important higher trophics of marine ecosystem which faced the several threats and conservation need in Gulf of Mannar, India.

Study Design: The study undertaken during extensive coral reef monitoring survey was carried out in Gulf of Mannar under the CRAM Project of National Centre for Coastal Research (NCCR). The present report emphasize the Morphometric observation of the dead Kogia sima and try to find out possible cause of death by examining in situ investigation.

Place and Duration of Study: The field study was taken in Vedalai Sea shore (N09 ${ }^{\circ} 15.626^{\prime}$, E79 ${ }^{\circ}$ 4.977') under the Mandapam Union of Ramnathapuram District of Tamil Nadu. The male whale specimen was found on $5^{\text {th }}$ May, 2019 lying dead on the sandy seashore. 
Methodology: Animal was photographed and morphological attributes were measured to identify the specimen. Several injuries have been highlighted in the paper which helps in investigating the cause of death.

Results: The Dwarf Sperm Whale was infant and has mild damage on the mouth parts including scuff off skin from the body and severe blood clotting at major part of the right side near to pectoral fin. Death of this infant is not clear but it is assumed that the male infant has lost from his parents and came to the inshore area of Mandapam where it gets stuck with running boat or boulder rocks as this immature whale limits its diving capabilities. The necessary morphological characters and measures have been listed in Table 1.

Conclusion: This unfortunate death clearly indicated that acute information on ecological behavior of Dwarf Sperm Whale is still under data collection stage in India and that previous conservation efforts in country must be reviewed in terms of role of local authorities, live stranded cetaceans and hunting or incidental killing which in future can build a road map for effective action plans to save this marine mammal.

Keywords: Dwarf sperm whale; Kogia sima; flagship animal; mandapam; gulf of mannar.

\section{INTRODUCTION}

Indian coastal water comprised of 30 cetacean species which are included under IUCN Red Data list as endangered, vulnerable, near threatened, least concerned and data deficient. 14 species of Cetaceans are found in Gulf of Mannar of India and hence it is considered as Cetacean hotspot of India [1]. Kogia sima has been scheduled under the category I species of Wildlife Protection Act of India [1]. This animal is widely distributed in temparate and tropical waters of Atlantic, Pacific and Indian Oceans $[2,3,4]$. Kogia sima usually occurs mainly in seaward from the continental slope to deep ocean waters and inshore appearance of this Dwarf Sperm Whale is uncommon [4,5]. India represents $25 \%$ distribution of the worlds' total marine mammals and particularly Kogia sima in Indian waters are very limited and poorly understood $[6,7,8]$. It has been recorded so far from Gulf of Mannar, and Lakshadweep Islands of India [8]. Adults are usually dark grey while the infant has uniformly light or dark grey on the dorsal side and cream or white colour on ventral side. Two representative of the genus Kogia, called as Kogia sima and Kogia breviceps are closely identical. The position and length of the dorsal fin is the noticeable characteristic to differentiate the two species during field based observation. In Kogia sima, dorsal fin is positioned approximately midway along the back and is relatively tall, whereas in Kogia breviceps, the fin is positioned posterior to the midpoint of the back and is relatively short [4]. The present study reports the death of male Dwarf Sperm Whale in Gulf of Mannar whose morphological characters is measured and highlighted the threats and risk to the poorly known marine mammals in Indian Ocean.

\section{METHODOLOGY}

On $5^{\text {th }}$ May 2019, a dead male infant of Kogia sima was recorded in nearshore area located at $1 \mathrm{~km}$ west (N09'15.626', E79 $\left.{ }^{\circ} 04.977^{\prime}\right)$ of Vedalai village under the Mandapam Union of Ramnathapuram district. Animal was photographed and morphological attributes were measured to investigate the cause of death $[9,3]$. Present study aims to highlight an accidental death of this flagship species and to discuss the existing threats and conservation need of marine mammals in Gulf of Mannar, India.

\section{RESULTS AND DISCUSSION}

The animal was $1.2 \mathrm{~m}$ in length and $73 \mathrm{~kg}$ in weight. No damage was observed on the dorsal side of the body (Fig.1a). Morphological characteristics were clearly distinguished as the specimen was not spoiled (Fig.1a-b). Mouth is rounded and upper jaw is blunt compared to Kogia breviceps (Fig.1 e-g). Morphometric measurements were also documented at the stranded site (Table1). Internal organ and tissues were intact which presents normal coloration and texture. No bad odor comes from the dead body which may indicate recent death. Major part of Right Lateral side near to pectoral fin was found to have internal blood clotting (Fig.1c). Two to three small injuries were found upper part of mouth which seems to be occurred due to scratch from sharp objects (Fig.1d, 1g-h, I). No net marks were found on the carcass. A slight depression was noticed near the blow hole and 
surface of the rounded head (Fig e-g, i). This mark usually indicates that the infant was starved for a few days which may be one of the assumed cause of death. Blood coming out from the umbilical scar of the animal has been found while it was sighted on the sea beach (Fig.1j-k). This may occur due to hard hit by some object on the thorax and lateral side of the body. Dwarf Sperm Whales are rare in Indian waters and very limited distribution information is available about this flagship animal which help in regulating the higher trophic structure in marine ecosystem $[10,8]$. The sighting of live Kogia sima in the wild is challenging because of their inconscipicous movement in water, long dive to sea, deep water ecology and avoidance behavior in response to approaching boats [11]. Therefore, most of the distributional and death report made from historical notes, stranded specimens and accidental catch by fishermen while fishing. In Indian Ocean, few sighting of Dwarf Sperm Whales have been documented from the waters of North of the Seychelles to Oman and Sri Lanka, Thailand, Indonesia and Western Australia [2]. However, in recent times, stranded and dead bodies of Dwarf Sperm Whale were recorded from San Jose of Escuintla on $27^{\text {th }}$ February, 2013 [12]; Utila of Huonduras in Carribean Sea on 24 ${ }^{\text {th }}$ June 2019 [11]; Colombia in Carribean Sea on March 2019 [13]; Nicaragua of Central America on December 2020 [14]. In the present study, this is the first stranding report of Kogia sima from Gulf of Mannar, India. Earlier published literature reported the presence of Kogia sima from Andaman waters [15] and another report documented from Vizagpatam by Pillai [16] [17]. On $5^{\text {th }}$ March, 2014, a carcass of Kogia sima was found by Volunteers of the TREE foundation near Nainarkuppam of Uthandi. Eaxct cause of the death is not clear (The Hindu 2014). On March 2016, another dead body of $8 \mathrm{~m}$ long Kogia sima was reported from Palolem beach of South Goa [18]. Recently another three dead bodies are recorded from Indian waters; one from Lakshadweep Archipelago of Indian Waters on $27^{\text {th }}$ August, 2016 [8], Vimbvel Beach of North Goa on $7^{\text {th }}$ September, 2019 [19] and other from Dumas shore of Surat District in Gujarat on 08 December, 2021 [20]. Such reports are very crucial to understand the threats of marine mammal presently facing due to several anthropogenic pressures at the coastal region. Most of the cases, exact cause of death is unknown to the marine biologist and marine managers. The present study recorded sixth stranding report of Kogia sima from Indian waters and first report from Guilf of Mannar coast.
Moreover, the earlier and present report was one of the roughly 90 documented cases of whale and dolphin strandings along the Indian shores in the past 4 years. In the present study, the exact cause was not revealed and postmortem investigation was not allowed due to administrative constraints. Therefore, in situ observation revealed that the animal was an infant Dwarf Sperm Whale which might have lost his parents group and enter in inshore habitat near Mandapam. The injuries in body suggested that this animal might had died due to hit by the running boat or it stuck to the large rocks or corals while swimming. Earlier studies on stranding of cetaceans have proven data that more than $30 \%$ stranded incident occurs due to fishing activities and potential traumatic injuries associated with boat and vessel strike $[21,22,20]$. As this is very young, it is obvious that it is not a mature swimmer and diver in shallow water. Mild depression on the head and near blown hole indicated that he was starved for few days and he might be enough weak to swim and hit by hard object which results in death. Gulf of Mannar and Palk Bay has also been succeptible to frequent massive algal bloom incident caused by Noctiluca scintillans which reults mass mortality of fishes at Mandapam coast since 2019. Production of organic toxic substances by $N$ scintillans could be a probable contributor to the stranding of Kogia sima. In 2009, similar incidents were reported from US Atlantic coast where the presence of the neurotoxin domoic acid associated with algal blooms in their offshore habitats may contribute to strandings of dwarf and pygmy sperm whales (Fire et al., 2009). However, More information is needed on their regional populations to help understand the causes of strandings and determine their susceptibility to natural and anthropogenic threats. Regarding the identification of Kogia sima, there is much uncertainty and conflicts of reliability in identifying characters [8]. However, some access limitations are also arised on the death of important species due to administrative procedures to follow in Marine National Park area which results to restrict the detail investigation. Present study therefore investigated the important morphological characters as used in earlier studies to clearly differentiate in between Kogia sima and kogia breviceps [8,11]. In India, current status and knowledge on Dwarf Sperm Whale is under the data collection stage [1]. Dwarf Sperm Whale occurs in temperate and tropical waters of Atlantic, Pacific and Indian Oceans but rarely sighted at sea [23]. Inadequate information of its 
distribution, abundance, and local threats to this species fail to address the proper conservation management plan by local government authorities and marine mammal researcher of the country. Despite the enforcement of laws, cases of accidental and intentional catch of Dwarf
Sperm Whale were reported from the South east coast of India. Systematic data collection on cetacenas, effective surveillance and environmental education are indispensable for minimizing the threats and developing suitable action plans to save Dwarf Sperm Whale.

Table 1. Morphometric measurements of a dead and stranded dwarf sperm whale

\begin{tabular}{lll}
\hline SI No. & Particulars & Measurements (in cm) \\
\hline 1 & Total body length & 120.0 \\
2 & Tip of upper jaw to eye & 9.0 \\
3 & Tip of upper jaw to blowhole & 13.0 \\
4 & Eye diameter & 1.7 \\
5 & Length of caudal fin & 24.0 \\
6 & Length of dorsal fin base & 13.6 \\
7 & Pectoral fin width maximum & 18.2 \\
8 & Umbilical scar to anus & 37.0 \\
9 & Body height at the dorsal fin & 24.0 \\
10 & Body height at the tail fin & 6.3 \\
\hline
\end{tabular}

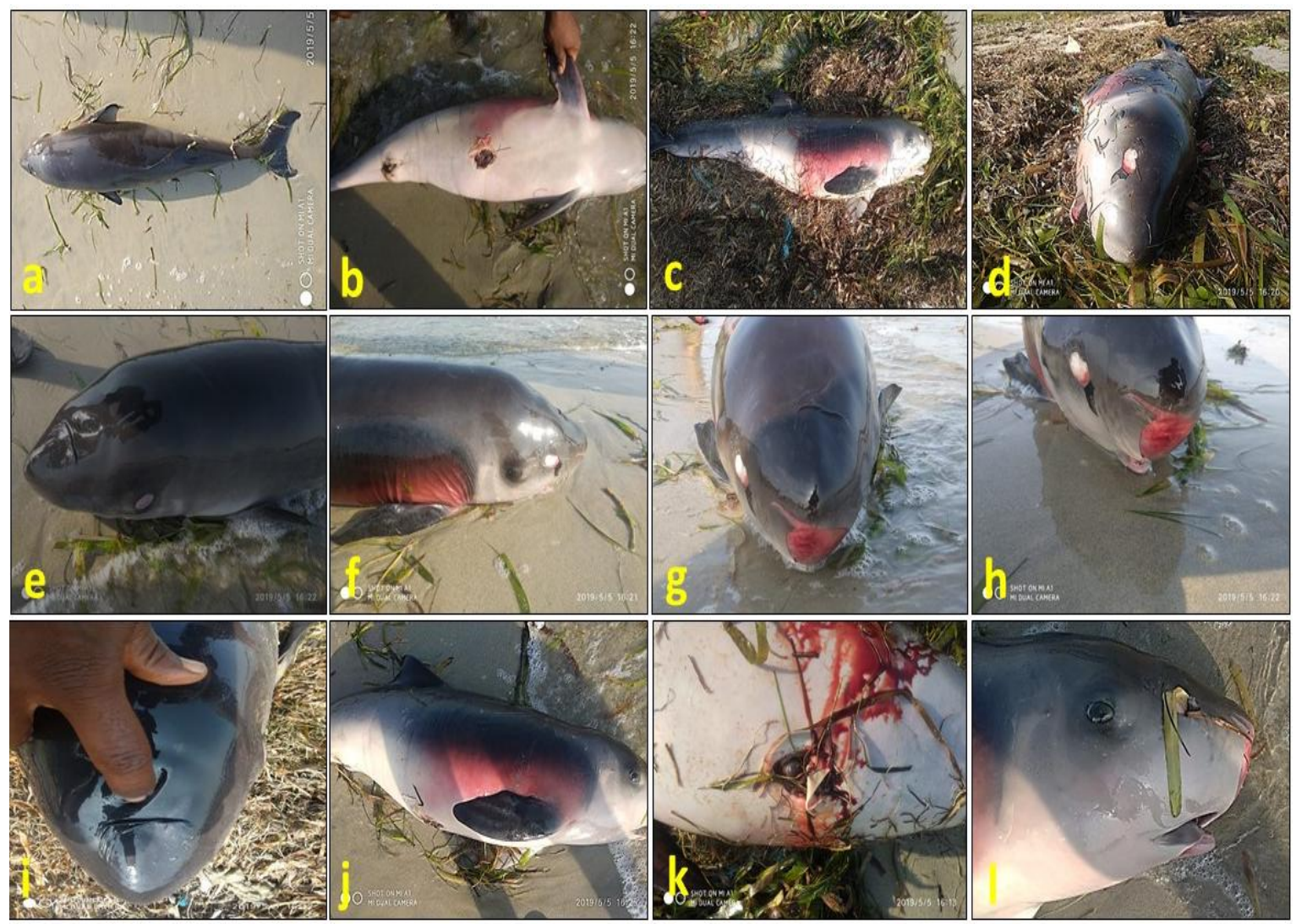

Fig. 1. Images of dead Dwarf Sperm Whale Kogia sima in Vedalai coast, a. dorsal view; b. ventral view; c. lateral view; d. scratch just above the right eye; e. mild depression on the head and near to blow hole; $f$. close view on the right side of the body showing major injuries; $g$-i injuries seen in head and mouth parts and blowhole region; j. major injuries leading to blood coagulation on the lateral side of the body; $k$. blood released from the Umbilical scar; I. No injuries on the upper and lower jaw of the mouth 


\section{CONCLUSION}

Kogia sima is a least concern (LC) marine mammals as per IUCN red list data and is also protected under Marine Mammals Protection Act (MMPA). The animal is an important part of marine trophic structure and their distribution are poorly known in Indian Ocean as well as in Indian waters. Present study highlights the morphological features of a Kogia sima in Gulf of Mannar which was found dead on $5^{\text {th }}$ May, 2019. Death of this male whale is not clear but it is assumed that the whale has lost from his group and came to the inshore area of Mandapam where it gets stuck with running boat or boulder rocks as this immature whale limits its diving capabilities. This is the sixth record of Dwarf Sperm Whale death in India since 2000. NCCR research team are undertaking surveys to find out more information on their distribution, reproduction, population characteristics, fishery interactions and pollutant levels which provide baseline knowledge to support conservation measures of cetacean in India.

\section{ACKNOWLEDGEMENTS}

The project is funded by Ministry of Earth Sciences, Government of India under Coastal Research scheme" implemented by National Centre for Coastal Research (NCCR), Chennai. Authors thank Secretary, MoES for constant encouragement and support to carry out the work. We sincerely thank the Chief Wildlife Warden, Ramanathapuram, Department of Environment and Forest, Government of Tamil Nadu, for providing logistic support and necessary permission to carry out the research work in Marine National Park. Authors also express sincere thanks to the field assistants for the field support.

\section{COMPETING INTERESTS}

Authors have declared that no competing interests exist.

\section{REFERENCES}

1. Kumarran RP. Cetaceans and Cetacean Research in India. Journal of Cetacean Research Manag. 2012;12(2):159172.

2. Bonato $M$, Webber MA, Attoumane $A$, Giacoma C. First record of Dwarf Sperm Whale (Kogia sima) from the Union of Comoros. Mar Biodiv Rec. 2016;9:37
3. Jefferson TA, Webber MA, Pitman RL. Marine mammals of the world, a comprehensive guide to their identification, second edition, Academic Press. 2015;616.

4. Baird RW. Sightings of Dwarf (Kogia sima) and Dwarf (K. sima) Sperm Whales from the main Hawaiian islands. Pacific Sciences. 2005;59:461-466

5. Caldwell DK, Caldwell MC. Dwarf Sperm Whale, Kogia sima (de Blainville, 1838); Dwarf Sperm Whale, Kogia simus (Owen, 1866). In: Ridgway SH, Harrison R (eds) Handbook of marine mammals, River Dolphins and the Larger Toothed Whales. Academic Press, London and San Diego. 1989;4:235-60,

6. Molur S, Nameer PO, Walker S. Report of Workshop Biodiversity Conservation Assessment and Management Action Plan for Mammals of India (BCPP-Endangered Species Project), Zoo Outreach Organisation, conservation Breeding Specialist Group, India, Coimbatore;1998.

7. Jeyabaskaran R, Vivekanandan E. Marine mammals and fisheries interactions in Indian seas. Regional symposium on ecosystem approaches to marine fisheries and biodiversity, Kochi WDCS, Marine Mammal Network, India;2013.

8. Aneesh Kumar KV, Baby ST, Dhaneesh $\mathrm{KV}$, Manjebrayakath $\mathrm{H}$, Sarvanane $\mathrm{N}$, Sudhakar M. A stranding record of Dwarf Sperm Whale Kogia Sima in Lakshadweep Archipelagpo, India and its genetic analogy by molecular phylogeny. Thalassas: An Int. J. Mar. Sci. 2018;35:239-245

9. Villapol LAB, Sayegh A, Leon T. Notes on the confirmation of Dwarf Sperm Whale Kogia sima Owen, 1886 (Cetacea: Kogiidae) on Venezuella Coast. Revista Scient UDO Agrícola, 2008;8(1):154162.

10. De Silva PHDH. Cetaceans (whales, dolphins and porpoises) recorded off Sri Lanka, India, from the Arabian Sea and gulf, Gulf of Aden and from the Red Sea. J Bombay Nat Hist Soc. 1987;84(3):505-525

11. Ramos EA, Luque API, Herrera L, Antúnez E, Brown TW, Castelblanco-Martínez N. Stranding of a pregnant dwarf sperm whale (Kogia sima) in Utila, Honduras. Lat American J Aqua Mammals. 2020;15:2529.

12. Wolford JO, Corona-Figueora MF, Davila V, Cabrera AA. Cetacean stranding records along the Pacific coastline of 
Guatemala, 2007-2021: Implications for management, conservation and research, Marine Policy. 2021;104827.

Available:https://doi.org/10.1016/j.marpol.2 021.104827

13. Mutis MA, Polanco A. First stranding record of Kogia sima (Owen, 1866) in the Colombian Caribbean, Lat American J Aqua Mammals. 2019;14:18-26.

14. Weerdt JD, Ramos EA, Pouplard E, Kochzius M, Clapham E. Cetacean strandings along the Pacific and Caribbean coasts of Nicaragua from 2014 to 2021. Mar Biodiv Rec. 2021;14:1-9.

15. Chantrapornsyl S, Kinze CC, Leatherwood $S$, Prematunga WP. Notes on the genus Kogia in the northern Indian Ocean. In: Leatherwood S, Donovan GP (eds), Cetaceans and Cetacean Research in the Indian Ocean Sanctuary, Marine Mammal Technical Report No. 3, United Nations Environment Programme, Nairobi, Kenya; 1991.

16. Pillay RSN. List of cetaceans taken in Travancore from 1902 to 1925 . J Bombay Nat Hist Soc 1926;31(3):815-817.

17. Sathasivam K. A catalogue of Indian marine mammal records. Blackbuck. 2000;16(2 and 3):23-74.

18. Online Published Report; 2016.
Available:https://www.wionews.com/world/ sharp-rise-in-whale-dolphin-strandingdeaths-in-india-91

19. Times of India Published Report;2019. https://timesofindia.indiatimes.com/city/goa /marine-stranding-dwarf-sperm-whalewashes-up-atvasco/articleshow/71056177.cms

20. WTI; 2021.

Available:https://www.wti.org.in/news/body -of-a-rare-dwarf-sperm-whale-found-insurat-coast/

21. Castro C, Van Waerebeek K. Strandings and mortality of cetaceans due to interactions with fishing nets in Ecuador, 2001- 2017, International Whaling Commission;2019.

22. Lozano PR, Fern'andez A, Saavedra P, Tejedor M, Sierra E, De la Fuente J, Xuriach A, Díaz-Delgado J, Rivero MA, Andrada M, Bernaldo de Quir'os Y, Arbelo M. Retrospective study of traumatic intrainterspecific interactions in stranded cetaceans, Canary Islands, Front Vetenary Sci, 2020;7:107.

23. Mcalpine DF. Pygmy and Dwarf Sperm Whales. Encyclopedia of Marine Mammals. 2018;936-938. DOI:10.1016/b978-0-12-373553-9.002121,2009

(c) 2022 Sadhukhan et al.; This is an Open Access article distributed under the terms of the Creative Commons Attribution License (http://creativecommons.org/licenses/by/4.0), which permits unrestricted use, distribution, and reproduction in any medium, provided the original work is properly cited. https://www.sdiarticle5.com/review-history/78257 